Forthcoming in Philosophical Psychology. This a pre-copy edited version. Please cite from the published version.

\title{
What Frege asked Alex the Parrot: Inferentialism, Number Concepts, and Animal Cognition
}

\author{
While there has been significant philosophical debate on whether nonlinguistic \\ animals can possess conceptual capabilities, less time has been devoted to \\ considering 'talking' animals, such as parrots. When they are discussed, their \\ capabilities are often downplayed as mere mimicry. The most explicit \\ philosophical example of this can be seen in Brandom's frequent comparisons of \\ parrots and thermostats. Brandom argues that because parrots (like thermostats) \\ cannot grasp the implicit inferential connections between concepts, their vocal \\ articulations do not actually have any conceptual content. In contrast, I argue that \\ Pepperberg's work with Alex (and other African grey parrots) provides evidence \\ that the vocal articulations of at least some parrots have conceptual content. \\ Using Frege's insight that numbers assert something about a concept, I argue that \\ Alex's ability to answer the question "How many?" depended upon a prior grasp \\ of conceptual content. Developing this claim, I argue that Alex's arithmetical \\ abilities show that he was capable of using numbers as both concepts and objects. \\ Frege's theoretical insight and Pepperberg's empirical work provide reason to \\ reconsider the capabilities of parrots, as well as what sorts of tasks provide \\ evidence for conceptual content.
}

Keywords: animal cognition, concepts, Frege, inferentialism, parrots

\section{Introduction}

Many philosophers are skeptical about the application of psychological concepts to nonhuman animals. ${ }^{1}$ On the other hand, as Andrews (2016) notes, "the cognitive scientists studying animals largely accept that animals are minded, cognitive systems" (p. 1). A standard response from philosophers, to the attribution of cognitive capabilities to animals, is to argue that the application of a term like 'belief' is not appropriate given a proper understanding of what belief really is. This strategy can be seen in the reaction 
to studies on the conceptual capabilities of pigeons, which purported to show they possessed the concept tree. The evidence cited was the ability of pigeons to reliably differentiate between photographs with trees in them and those without trees (Herrnstein, Loveland, \& Cable, 1976). In response, Allen and Hauser (1991) argued that "it is possible to teach a human being to sort distributors from other parts of car engines based on a family resemblance between shapes of distributors. But this ability would not be enough for us to want to say that the person has the concept of a distributor" (pp. 226-227). Therefore, there must be something more to having conceptual capabilities than simply the ability to sort one type of object from another. For many philosophers, linguistic capabilities play a necessary role in what it means to really have conceptual content (Brandom, 1994), really have beliefs (Stich, 1978), really have thoughts (Dummett, 2010), to really be rational (Davidson, 1982) to really make inferences (Bermudez, 2003), etc. But even when animals, such as parrots, are capable of vocal articulations that sound linguistic, philosophers are quick to dismiss such articulations as meaningless mimicry. Robert Brandom (2000) has given the most explicit articulation of this position in his frequent comparisons of the reports of parrots and thermostats (p. 48). Brandom argues that articulations from either lack meaning by positing a further requirement for conceptual capabilities: that one is able to grasp the inferential connections between concepts. For Brandom, a parrot's ability to correctly label red objects as 'red' does not actually demonstrate a grasp of the concept red if the parrot does not also understand that it follows that the object is not green (p. 48). My goal is not to argue for or against these further conditions for the attribution of conceptual capabilities. ${ }^{2}$ Instead, I will examine empirical work done by Irene Pepperberg on the cognitive capacities of African grey parrots (Psittacus erithacus) to see if parrots really are incapable of meeting Brandom's standards. ${ }^{3}$ 
In particular, I examine Pepperberg's work with her subject Alex, whom she worked with for a thirty-year period. Pepperberg (2006b) claims that Alex learned to apply labels to "more than fifty different objects, seven colors, five shapes, quantities to six, and three categories (material/color/shape)" (p. 471). More controversially, she claimed that his ability to combine "labels to identify, classify, request, or refuse approximately one hundred items and to alter his environment" was not merely mimicry but that Alex understood the labels he used (p. 471). For some, but not all labels, Pepperberg argues that Alex's capabilities should be understood as conceptual. She writes 'he understands that the label 'green' expresses the concept of greenness, which applies to beans as well as to training objects, and that the arbitrary label 'green' is subsumed into a category whose arbitrary label is 'color"' (p. 471). I think that Pepperberg is right to identify Alex as having conceptual capabilities, but I suspect the tests she used to show that Alex grasped color concepts are unlikely to be very convincing in light of Brandom's inferentialist objections. Instead of seeing Alex's abilities to apply the categorical labels of material, color, or shape to items as demonstrating conceptual competence, I argue that the numerical judgements made by Alex show an understanding of the inferential connections between concepts.

Building on an argument from Frege's (1884/1950) Foundations of Arithmetic, I argue that numerical abilities presuppose conceptual abilities. Frege's analysis of the question 'How many?' led him to argue that number statements are statements about concepts (§ 46). The question 'How many?' is then always 'How many X?', whether it is implied or explicitly articulated. An answer to the question 'How many?' therefore requires a grasp of the inferential connection between the number and the conceptual category one must count. Alex's ability to answer the question 'How many?' therefore shows that he grasped the inferential connections between at least some concepts. I will 
highlight this by showing that, not only can Alex grasp inferential connections, but that he is capable of treating number words as either concepts or objects. It follows that even if the conditions for Brandom's skepticism about the conceptual capabilities of parrots are accepted, at least some African grey parrots are capable of meeting them. Finally, I will consider two objections to my argument: (1) Alex does not have a sufficient number of inferential connections to really grasp concepts, and (2) Alex's ability to answer numerical questions, like the horse Clever Hans, does not actually demonstrate that he understands number concepts. The first objection helps deepen the understanding of the requirements for conceptual content, but I argue that further experimentation by Pepperberg on the production-comprehension distinction shows that Alex still passes this more sophisticated interpretation, while the second objection fails to consider the many ways Pepperberg controlled for inadvertent cuing. While I will mostly focus on the work of Brandom, Frege, and Pepperberg, the conclusions that I draw from their work are relevant to broader questions about the nature of concepts, and how to investigate concept acquisition and possession.

\section{Brandom's Inferentialist Framework}

One of the central projects of philosophy, since at least the early modern era, has been to establish what makes humans different from the other creatures around them. Brandom (1994) sets up this type of demarcational project as an investigation into what it means to use the term 'we' (p. 3). He argues that 'we' are sapient while others are merely sentient, meaning they show "irritability or arousal" instead of "understanding or intelligence" (p. 5). Sapience is a form of "concept-mongering" which for Brandom means that one has the ability to interact with their environment through the flexible and reliable application of and response to concepts (p. 8). In the same way that Kant (1785/1996) uses the category "rational beings", (p. 79), Brandom (1994) avoids 
straightforward speciesism by admitting that the capacities identified with the 'we' may be found in "beings quite different from us" (p. 5). ${ }^{4}$ Demarcating between these types of beings is then a matter of figuring out which ones are capable of concept-mongering.

One way of determining who has conceptual capabilities is to ask if the being in question also has linguistic capabilities. For example, Dummett (2010), drawing from a passage in Frege's Foundations, has argued that animals are only capable of "protothoughts" (p. 119). ${ }^{5}$ Imagining a scenario where a dog stands its ground if it is attacked by one dog, but runs away if it is attacked by more than one dog, Dummett argues that it is not possible to attribute number concepts to the dog. He goes as far to say that "no canine behavior is conceivable that would warrant the attribution" (p. 118). The reason for reaching this conclusion is that "we have no linguistic means of expressing just what it is [the dog] recognizes" (p. 118). While there are important complications in Brandom's account, his exclusion of non-linguistic animals from the domain of concept use rests on similar concerns. Brandom's (2000) project, which he calls inferentialism, is a rejection of the idea that concepts are mental representations. Instead, concepts are "applied in the realm of language by the public use of sentences and other linguistic expressions" (p. 5). Historically, the acquisition of language was considered a matter of learning to represent one's mental contents, but for Brandom, the acquisition of the concepts that reside in the "realm of the mind" is dependent upon their initial employment in the public sphere (p. 5). Creatures that lack language, such as Dummett's dog, are not able to enter into the linguistic space in the ways necessary to acquire conceptual capabilities. Attributing mental content, such as the concept one, ignores the initial steps required to possess such a capacity.

But using language to demarcate between those who possess conceptual capabilities and those who lack them leaves a question of how to classify 'talking' 
parrots and signing apes. In other words, how should the vocal articulations of parrots be interpreted? Are parrots only capable of meaningless mimicry or is it possible for their articulations to possess actual conceptual content? With regard to Pepperberg's research: what would indicate that Pepperberg's parrots demonstrate actual understanding instead of just clever mimicry? As the studies of pigeons mentioned earlier show, some scientists have taken the correct application of labels to demonstrate conceptual capabilities. Brandom, perhaps more directly than any other philosopher, has argued that a similar demonstration by a parrot would not involve conceptual content. For Brandom, if Pepperberg's parrots, are merely providing the correct descriptive labels when shown a physical object, then, like nonlinguistic animals, they are not members of the 'we'.

Brandom often describes parrots and thermostats as inhabiting the same category, arguing that a parrot that has been trained to identify red things, like a thermostat that beeps when it is below a certain temperature, fails to make a semantically meaningful utterance. He writes that the responses provided by parrots and thermostats are not meaningful to either (2000, p. 48). Brandom sees this as a consequence of his view that for an articulation to have conceptual content it has to "play a role in the inferential game of making claims and giving and asking for reasons" (p. 48). Brandom writes:

To grasp or understand... a concept is to have practical mastery over the inferences it is involved in - to know, in the practical sense of being able to distinguish (a kind of know-how), what follows from the applicability of a concept, and what it follows from. The parrot does not treat "That's red" as incompatible with "That's green," nor as following from "That's scarlet" and entailing "That's colored." Insofar as the repeatable response is not, for the parrot, caught up in practical proprieties of inference and justification, and so of the making of further judgments, it is not a conceptual or a cognitive matter at all (p. 48). 
Intuitively, this makes a lot of sense. If someone is able to apply the label 'rabbit' when she encounters rabbits, but does not know what an animal is, it is reasonable to ask if she ever really understood the concept rabbit.

Since concepts are bound up in an inferential game of giving and asking for reasons, having conceptual capabilities is a kind of mastery that involves understanding the connections and relationships between the concepts one is using. One cannot give or ask for reasons for why a certain label applies if one does not understand the ways in which concepts are inferentially linked. A label has to be able to "serve as at least as a premise from which to draw inferential consequences" otherwise "it is not functioning as a concept at all” (Brandom, 2000, p. 49). In order to grasp any one concept, one must also grasp a cluster of other inferentially related concepts. Even if one uses a concept non-inferentially, such as "That's red", the person making the utterance has to be capable of using the concept inferentially if it is to have conceptual content. So, if all Pepperberg's parrots are able to do is apply labels, without understanding anything that follows from their application, such as what other labels can or cannot be applied, then one should be skeptical about Pepperberg's claims.

To summarize, on Brandom's view, even if a parrot is capable of categorizing things with the correct labels, this behavior does not reach the level of mastery necessary for genuine conceptual content. A parrot is not able to grasp the inferential connections between the category it is applying and the other categories that would be appropriate or inappropriate to apply given its application. The application of a category is therefore not automatically conceptual. For Brandom, because parrots lack the necessary conceptual capabilities, 'we' can safely consider them to only be sentient. Fortunately for Pepperberg's work, Alex demonstrated that he was capable of much more than reliably squawking "That's red." In the following section, I describe some of 
Pepperberg's training and testing procedures with Alex. In particular, I emphasize the ways in which Pepperberg's breakthroughs come from insights that mirror Brandom's inferentialism.

\section{The Model/Rival Technique and the Sociality of the 'We'}

Pepperberg (2006a) trained Alex to identify and classify "various objects, materials, colors, and shapes" using a technique called the Model-Rival (M/R) procedure (p. 378). Pepperberg's use of M/R was explicitly aimed at "the development of social cognition" (Trestman, p. 95). The failure of many previous attempts to train birds by other researchers created a puzzle: "why these birds, which were so vocal in the wild and which learned allospecific vocalizations so readily in the informal setting of a home, were incapable of significant vocal learning under well-controlled laboratory conditions" (Pepperberg, 1999, 15). Ethological work on tropical birds in the wild began to make clear the importance of the birds' social environment and the $M / R$ technique was developed by Todt to take advantage of this insight (Pepperberg, 1999, pp. 15-16). Todt's version of $M / R$ was to have two people play the roles of parrots to model the interactive form of communication they wanted the parrot to learn. Compared to previous approaches, Todt's technique was remarkably successful, but only showed that the parrots could learn to imitate human vocalizations. What his work did not show was whether the birds understood the vocalizations as meaningful (Pepperberg, 1999, p. 16).

Pepperberg modified the M/R technique based on two insights about the role of context in learning. The first she draws from the work of Piaget who emphasized the interaction between subjects and their environment in the learning process. Pepperberg (1999) writes that learning is a process of integrating new patterns into old ones (p. 19). Therefore, "a crucial factor is that the subject's environment provides experiences that 
encourage such 'assimilation' and 'accommodation'...a concept or behavior is more likely to be assimilated if it has functional value for the student, particularly if this functionality is demonstrated explicitly" (p. 19). In other words, if the subject can be shown the practical value of the content she is learning, then she is more likely to integrate the new content into already existing patterns of behavior. The second insight, drawing from the work of Vygotsky, is that learning involves being able to transfer a skill from one context to another. Teaching, then, must include a "bridge" from the initial contexts to novel ones (p. 19).

Describing the application of these theories to her teaching process, Pepperberg writes:
In a typical interaction, the bird is on a jungle gym, its cage, or the back of a chair and observes two humans handling some objects in which he has already demonstrated interest (perhaps has used them as preening implements). While the bird watches, one human "trains" the second human. The trainer presents an object, asks questions about the object (e.g. "What's here?" "What color?" What shape?"), and gives praise and the object itself as a reward for a correct answer. [...] ...the second human is a model for the bird's responses and a rival for the trainer's attention. The model/rival occasionally errs (produces garbled utterances, partial identifications, etc., that are similar to mistakes being made by the bird at the time). Disapproval for an incorrect response is demonstrated by scolding and temporarily removing the object from sight. Because the human model/rival is, however, encouraged to try again or talk more clearly (e.g., "You're closer; say better"), the procedure also allows the bird to observe "corrective feedback"... (p. 26).

One important aspect of this process is that the trainer and the model/rival sometimes switch and the bird is included in the process as an active participant, so that the bird understands that communication is reciprocal and generalizable to new contexts (p. 26). The process is not a matter of one-to-one associations. The parrot is taught through a series of sentence frames such as "Here's paper!" or "Such a big piece of paper!" (p. 
28). The emphasis on words as parts of larger wholes is made to both limit simple straightforward imitation and help the subject grasp the connections between concepts and the ways they can be used. Trestman (2015) has argued that the success of Alex's learning process is, in part, a consequence of the social nature of Alex's training that emphasized the connections between labels (pp. 93-95). He points out that older methods that took a more atomistic approach were not nearly as successful as Pepperberg's (pp. 92-93). These inferential connections are the most apparent in Alex's use of the number of corners of a shape as the label for that shape (e.g. "three-corner" instead of triangle) (2006a, p. 379). Alex, had therefore, already learned certain number labels before being taught how to reapply them to more abstract quantitative judgements. Alex also on occasion tried novel combinations of labels that he had not been taught, such as combining "rock" and "corn" (p. 240). When Alex asked for "rock corn" the researchers gave him a dried corn kernel which he ate. Pepperberg is careful not to read too much into these vocal articulations, but encourages them on the possibility that Alex is developing new connections (p. 239).

I suspect that an inferentialist might find Pepperberg's insights into how to successfully train parrots oddly familiar. Brandom (2000), for example, states that one can distinguish sapient beings from sentient beings because sapients have the "practical know-how to situate that response in a network of inferential relations... For the knower, taking something to be red or cold is making a move in a game of giving and asking for reasons..." (p. 162). If seeing, giving, and asking for reasons are a constitutive part of conceptual content then "conceptual content is not only inferentially articulated but also socially articulated" (p. 163). In other words, the conceptual is always bound up in social practices. Considering the emphasis of sociality, the 
pragmatic value of words, and encouragement of novel responses, Pepperberg's $M / R$ technique begins to look like an attempt to bring her subjects into the 'we' ${ }^{6}$

Pepperberg (1999) herself emphasizes what she calls categorical labels when arguing that Alex can grasp concepts. She writes:

I needed to determine if he could respond not only to specific properties or patterns of stimuli, like pigeons who respond to positive instances of "tree", but also to classes or categories to which these specific properties or patterns belong. Could he, for example, go beyond recognizing what is or is not "green" to recognizing the nature of the relationship between a green pen and a blade of grass? (p. 52).

In order to test this distinction, Alex was shown objects that had multiple features and asked to provide the answer to queries about those features in a single session. Pepperberg labels this ability "reclassification" since Alex would need to categorize an item one way before having to apply a different type of category to it (e.g. shape and then color) (p. 54). While discovering that Alex was capable of this task shows a certain level of sophistication, it is not clear that it actually demonstrated conceptual competence. The test shows that Alex was capable of answering different queries about the same object and that he was able to apply more than one type of label to the same object. But an inferentialist is unlikely to find this convincing because the connection between the types of categories, Alex is being asked about, are not necessarily inferential. Inferential connections would be better displayed if Alex was capable of knowing that another category did or did not follow from the application of the initial label. In contrast, Alex's numerical capabilities do demonstrate the inferential connections necessary for conceptual content.

Pepperberg (2006a) began training and testing Alex on numerical competencies after several years of working with him on identifying other labels such as color and shape. She notes that this would mean that Alex could identify a "novel class" because 
being able to answer the question "How many?" would require him to "categorize items based on physical similarity within a group and a group's quantity, rather than solely by physical characteristics of group members" (p. 378). Simply based on the number of steps involved, applying number labels is a more complicated process than identifying shape or color. In the following section, I argue that the application of number labels shows something more than just an ability to handle processes that involve more cognitive steps. The inferential structure of asking and responding to the question "How many?" shows that Alex's responses contain the inferential connections necessary for conceptual content.

\section{The Link between Conceptual and Numerical Content}

In The Foundations of Arithmetic, Frege (1884/1950) provides an analysis of the concept number, based on what is required to answer the question "How many?" In particular, Frege argues that "the content of a statement of a number is an assertion about a concept" (§ 46). Frege means that an answer to the question "How many?" only makes sense if a concept can be identified. Explicating Frege's view, Klement (2012) points out that "in making such claims as "Here are 500 men," "Venus has 0 moons," and "the King's carriage is drawn by four horses," I am predicating something about the concepts men that are present, moon of Venus and horse that draws the King's carriage" (p. 148). For Frege, concepts are a "species of functions" that can be identified by "predicative or incomplete expressions" (Klement, 2012, p. 149). For example, “ is a dog" is an unsaturated concept whereas what saturates it (e.g.

Clifford) is an object. So the question "How many?" is a question about the object (i.e. the number) that saturates the explicitly articulated or implied concept.

Frege's approach was motivated by the fact that other theorists could not make sense of the possibility of counting the same set of objects in different sorts of ways. If 
one is handed a deck of cards and asked "How many?" one does not yet have enough information to answer the question. In other words, one has not yet been given "completely the object he is to investigate; I must add some further word - cards, or packs, or points" (Frege, 1884/1950, § 22). From examples like these, Frege draws the preliminary conclusion that numbers are second-order concepts - meaning that a "number is simply something that can be predicated of a concept" (Klement, 2012, p. 148). ${ }^{7}$ The number one then, is the concept under which exactly one thing falls. For example, the statement 'there is one author of Treasure Island" can be analyzed as saying that there is one thing that falls under the concept 'author of Treasure Island'. Frege avoids the circularity that might seem implicit in this definition by defining numbers purely logically. For example, two is the concept $\mathrm{F}$ which the distinct things $x$ and $y$ fall under, and anything that falls under $\mathrm{F}$ is identical to $x$ or $y$ (Zalta, 2016, p. 25).

The connection between numerical judgements and conceptual assertions is born out in Alex's education. In the initial trials, the form of the question asked is not just "How many?" but "How many X?" Frege's insight about what is required to answer the question "How many?" means that it is necessary for X to play a compositional role in the way Alex can be asked the question and what is necessary for him to grasp in order to answer it. A simple "How many?" cannot have a right or wrong answer unless the concept to be counted is implied or made explicit. For Brandom, the inferential connections between concepts are what fixes the content of a given concept, and Frege's insight works out what this means for number concepts. So, for example, the exact structure of the inferential relationship that composes the concept two is worked out by Frege to be (in contemporary notation): $\exists x \exists y[\mathrm{~F} x \& \mathrm{~F} y \& x \neq y \& \forall z(\mathrm{~F} z \rightarrow(z=x$ $\mathrm{v} z=y))]$. What this sentence expresses is the logical structure implicit in the inferential connections, that Alex must grasp, in order to provide the right answer when asked 
"How many X?" In other words, he must grasp the concept F (e.g. red thing on the tray), that $x$ and $y$ are distinct things (e.g. a red key and a red toy car on the tray presented to him), and that nothing else falls underneath F. It would be a mistake to conclude from Frege's analysis of number statements that Alex must understand predicate logic in order to grasp the concept two. After all, many humans find predicate logic positively alien, and many of them are perfectly capable of grasping the concept two.

Instead, Frege's analysis makes explicit, what is implicitly involved in making a numerical judgement. Furthermore, the actual articulation can be relatively simple as long as it is a move in a language game. Brandom (1994) makes this point by writing:

Sentences are expressions whose unembedded utterance performs a speech act such as making a claim, asking a question, or giving a command. That is why even when such a speech act is performed by an utterance that does not manifest the syntactic complexity typical of sentences (a shout of "Rabbit!" or "Fire!" for instance), the utterance should nonetheless be interpreted as a one-word sentence, as meaning what we might express by "Look at the rabbit!" or "There is a fire!" (p. 82).

So while Alex's utterances may be syntactically simple, the ways in which he is brought into simple language games through the $\mathrm{M} / \mathrm{R}$ technique means that one should be willing to interpret his sentences similarly to the way Brandom interprets someone yelling "Fire!"

Since asking and answering the question "How many?" requires an implicit connection between the numerical label and the concept that the items fall under, an investigation into numerical capabilities can show a lot more than the application of other types of labels. In fact, for an inferentialist, the ability to apply numerical labels could then be considered an important testing point for evaluating who does and who 
does not possess conceptual capabilities. This puts Pepperberg's focus on Alex's numerical abilities in a new and interesting light; if Alex was able to appropriately answer the question "How many?" it shows something more significant than his ability to identify other sorts of objects.

As mentioned earlier, Alex had already learned some numerical words by using them to identify shapes, such as 'four-corner' for square. Moving from descriptive labels to quantitative ones was initially introduced by correcting mistakes when he had to label an item that had x-number of corners. For example, if Alex called a wooden triangle "three wood" instead of "three-corner", a trainer would correct him by holding up three wooden items and saying "Here's three wood" before re-asking "Now, what's this?" about the wooden triangle (Pepperberg, 1999, p. 100). They then began to train him on the labels "two" and "five" with the M/R technique on sets of objects (pp. 101102). In order for Alex's response to be considered correct, he had to provide both the numerical label and the item label (e.g. five wood) (p. 102). Pepperberg then tested the inferential connection in the opposite direction by showing Alex shapes with two or five corners to see if he could apply his newly learned numerical labels back to shapes (p. 102). Alex, therefore, learned numerical labels and the labels of shapes in both directions, for some (three and four), he began by learning how to answer "What's this?" before learning how to reapply those labels to "How many?", and for others (e.g. two, five, and six), he learned "How many?" before "What's this?"

In initial tests, Alex was able to label sets less than or equal to six with $78.9 \%$ accuracy, and "items did not need to be familiar nor in any particular pattern" (Pepperberg, 2006a, p. 380). Interestingly, Alex performed slightly better than two-anda-half-year old human children generally do when having to identify subsets within heterogeneous sets of two different types of objects. Alex responded correctly $70 \%$ of 
the time in the initial trials. Pepperberg adapted a human testing process that used distractors in later tests, in an attempt to determine whether Alex was subitizing or counting. Alex was shown "confounded number sets (quantities of four sets of items varying in two colors and two object categories - e.g. blue and red wood and red wool) and was asked to enumerate items uniquely defined by both one color and one object category" (p. 381). Alex's accuracy in these tests was comparable to human abilities, but the errors that he did make might indicate instead of subitizing smaller numbers and counting larger numbers like humans do, it is possible that he is subitizing all quantities(p. 382). Whether Alex was subitizing or counting, both depend on first identifying the relevant concept for the object to fall under. It would therefore seem that Alex was capable of drawing the implicit connections that Brandom argues are necessary for the attribution of conceptual capabilities.

Some readers might be concerned that my Fregean analysis of Alex's articulations may be a little hasty considering that Frege seems to reject his interpretation of numbers as second-order concepts only two paragraphs after introducing it. Based on several different worries, Frege (1884/1950) argues that numbers are actually the extensions of concepts instead of concepts themselves (§ 68). One of the major reasons Frege settles on this definition and not the former is so that numbers can be identified as objects, given that numerals do not seem to fit the predicative form of concepts (Klement, 2012. p. 149). Drawing from a distinction suggested by Zalta's (2016) analysis, I think a more reasonable understanding is to take Frege's initial analysis as an interpretation of the compositional structure of number statements and the latter definition as Frege's analysis of the structure of natural numbers (pp. 24-30). Klement (2012) develops this distinction by arguing that "the extension of a concept is nothing but the concept itself considered as an object, rather 
than as something incomplete or predicative" (p. 150). In other words, Frege is making a distinction between number concepts and the objects of arithmetic.

In Frege's (1892/1997) discussion of the infamous problem of the concept horse he writes:

In logical discussion one quite often needs to say something about a concept, and to express this in the form usual of such predications - viz., to make what is said about the concept into the content of the grammatical predicate. Consequently, one would expect that the reference of the grammatical subject would be the concept; but the concept as such cannot play this part, in view of its predicative nature; it must first be converted into an object, or more precisely, an object must go proxy for it. We designate this concept by prefixing the words 'the concept', e.g.,

'The concept man is not empty.'

Here the first three words are to be regarded as a proper name, which can no more be used predicatively than 'Berlin' or 'Vesuvius' (p. 185).

Klement (2012) reads this passage as saying that "for every concept, there is an object which the concept 'converts into', or which goes proxy for the concept, when we attempt to think of the concept itself as the subject of what we are claiming" (p. 152). To be an extension of a concept just is to be a proxy-object (p. 154). While Klement provides a lot of textual evidence for this reading, I will only note that Frege's motivation for treating numbers as objects is that arithmetic needs numbers that are “conceived not as a dependent attribute, but substantively" (Frege, 1884/1950, § 106). But even here he maintains that "a statement of numbers asserts something objective of a concept" $(\S 106)$ meaning that his talk of extensions does not deny the conceptual structure of number statements.

What does all this mean for evaluating Alex's cognitive abilities? Even if numbers are the extensions of concepts instead of second-order concepts, the conclusion remains that inferential connections between concepts are necessary in order to ask and 
answer number questions. But if we accept Klement's interpretation that extensions are proxy-objects, then Frege has provided a more fine-grained tool for analyzing those conceptual links, because it is now possible to ask if Alex is capable of, not only using number concepts, but also using numbers as objects. While rearranging sentences to treat concepts as objects is clearly beyond Alex's abilities, if Klement's analysis is correct, then arithmetical processes are enough to show that Alex can treat numbers as objects.

Pepperberg (2006a) started testing Alex on basic arithmetic without specifically training him for the procedure (p. 385). The basic process was to have several items under two different cups. The tester would lift one cup to show Alex its contents, put it back down and lift the other cup (p. 385). After the second cup was put down, Alex was asked "How many total?" Alex was tested on summing up to six, including cups that had nothing underneath them which Pepperberg took to denote zero. His first trial score for each sum was $84.3 \%$, but Alex had particular trouble summing $5+0$, consistently providing the answer "Six" even when corrected (p. 386). He also struggled with $0+0$ when there was nothing under either cup, sometimes refusing to answer, and other times providing the answer "One" (pp. 386-387). Alex previously had, without being trained to, used the word "none" when asked to identify a numerical set by its color on a tray that lacked a subset with that numerosity. Pepperberg writes that Alex "initiated the topic" without prompting (p. 384). Further tests on Alex's use of "none" seem to show that his use of the label did not line up exactly with the concept zero ("a specific numerosity") but instead the "absence of a designated number of items" (p. 387). Considering both the abilities of human children to understand zero (Pepperberg (2006a) points out the difficulties that autistic children have (p. 387)), and the history of mathematics, it is not entirely shocking that Alex struggled with zero. Right before 
Alex's death, Pepperberg (2012) began testing him on a similar task that involved Arabic numerals underneath the cups instead of items (pp. 712-713). Given the cognitive complexity of such a task, Alex's initial trial scores were impressive at $75 \%$ accuracy (p. 714). Unfortunately, Alex's untimely death limited the extent of testing Pepperberg was able to do with him on these tasks.

Given these results, it possible to claim that Alex had some ability to treat number concepts as objects, or to use Klement's language, as their proxy-objects. From an inferentialist perspective, being able to use numbers as both concepts and objects shows an ability to use number concepts in different roles or contexts in the types of ways an inferentialist would look for in order to evaluate if one can be admitted into the 'we' of concept-mongers. Frege's analysis of number statements shows that in order to be able to ask and answer questions about quantities one needs to be able to grasp the inferential connection between the concept that the items fall under and the number concept. Alex's ability to appropriately apply number labels then shows something above and beyond his ability to apply color or material labels. Furthermore, the tests on his ability to do basic addition shows that he is still able to manage those labels when they are treated as objects instead of second-order predicates. In the following section, I provide a possible inferentialist objection to this analysis of Alex's conceptual capabilities. In addressing this objection, I think we can get a more sophisticated view both of what inferentialism requires to enter the 'we' and how exactly Alex can meet that criterion.

\section{The Application and Consequence of Conceptual Content}

One way Brandom and other inferentialists can respond to this argument is to admit that while Alex appears to grasp some inferential connections, Pepperberg's research does not show that he grasps a sufficient number of inferential connections for the attribution 
of conceptual capabilities. In other words, simply grasping some inferential connections is not enough to have conceptual content attributed to one's articulations; one must be able to meet a certain threshold of inferential connections before one truly has such capabilities. The assertion of a threshold must avoid entailing that a grasp of all the possible connections is necessary; otherwise, this would result in denying that anyone has ever grasped a concept. Brandom (1994) is well aware of the need to avoid this conclusion, writing that conceptual capabilities are "not an all-or-none affair" (p. 120). In order for this objection to be successful then, the inferentialist needs to find a threshold between all and some. But, it is important that the threshold not be arbitrary or question-begging (i.e. it has to do more than simply point to the number of inferential connections grasped by a neurotypical adult human).

In her discussion of other studies on animal cognition, Pepperberg (2006a) provides a useful example for understanding why this concern should be taken seriously. There are cases where apes and human children are able to apply a numerical label to sets of objects, but then are not able to perform other sorts of actions that one would presume would follow from knowing when to apply the label. She writes “children who succeed on 'How many marbles?'...may fail on 'Give me X marbles'; demonstrating that they really do not understand the relationship between the number label and quantity” (p. 382). Wynn (1990), whose research Pepperberg refers to here, does not consider this result to necessarily be a failure of conceptual competence. She writes that children can "fail even if they have conceptual competence, by not having learned appropriate procedures that instantiate their conceptual competence in a particular context" (p. 31). It is legitimate to worry though, that having conceptual competence, in contrast to the mere application of a label, is being able to use that concept in novel contexts. Pepperberg (2006a) seems less willing to attribute conceptual 
capabilities to the children as she describes it in terms of the comprehension-production distinction, meaning the children were able to produce the label but lacked actual understanding (p. 382). She points out that for human children, comprehension usually precedes production, so the case is a strange one (p. 382).

Brandom (2000) provides a useful diagnosis: he writes that grasping a concept is "practical mastery of a certain kind of inferentially articulated doing: responding differentially according to the circumstances of proper application of a concept, and distinguishing the proper inferential consequences of such application" (pp. 63-64). The children who can apply the number label, but are not able to hand over the correct number of marbles, have learned how to apply the correct label but have not grasped the consequences of applying it. Therefore, for Brandom, the children's ability to apply numerical labels lacks conceptual content because actual conceptual content relies on both the appropriate application, as well as understanding the inferential consequences of that application. Brandom (1994) argues that contemporary theories, to their detriment, have one-sided interpretations of meaning. For example, reliabilists focus too exclusively on application, and, in contrast, pragmatists focus too exclusively on the consequences (pp. 121-123). Brandom argues that any attribution of conceptual content depends on both of these capabilities. So the inferentialist objection can now be put to the test: was Alex able to demonstrate that he could both apply the label and comprehend the consequences of that application?

In order to establish if Alex's ability to produce a label also came with actual comprehension, Pepperberg (2006a) tested his ability to answer questions such as “'what color (object) [is] number $X$ ' where $X=1-6$ " when given a heterogeneous set of objects, without directly training him for the task (p. 383). Pepperberg writes: 
The procedure required that he comprehend the auditorially presented numeral label (e.g. ' 6 ') and use its meaning to direct a search for the cardinal amount specified by that label (e.g. six things), that is, know exactly what a set of ' $X$ ' individual items is, even when intermixed with other items representing different numerical sets. Items for each number were not clumped together, and each item of a particular set was generally closer to an object of another set than to one of its own. Alex could not perform the task without comprehending the number label. Each query also retested his ability to identify the object or color of the set specified by the numerical label (p. 383).

Alex was able to answer the question accurately $87.9 \%$ of the time, making no errors in his first ten trials (p. 383). Pepperberg states that his comprehension "surpassed children up to about 3 years old, who, for example, may point to each item in a set, state '1, 2, 3', but not understand that three items are actually present” (p. 383). It was during these tests that Alex, without having been directly taught the word, began using the label "none" when asked "what color is five?" for a collection of items that did not have a subset of five objects in it (pp. 383-384).

While Pepperberg's aim in these trials was to establish whether Alex was capable of comprehension as well as production, it also clarifies if Alex was capable of understanding numerical labels in a way that allowed him to infer a consequence of its application. He was able to use a numerical label to search for a set of items and then articulate the color concept those items fell under. In the trials that tested production, Alex was answering questions of the form "How many X?" whereas in the trials that tested comprehension, Alex was asked questions of the form "What color is X?" In the former task, Alex's job is to use the first-order concept (e.g. red thing) to identify a set of objects and then provide the second-order concept (e.g. two). In the latter task, Alex's job is to use the second-order concept (e.g. two) to identify a set of objects and then provide the first-order concept (e.g. red thing) that falls under that second-order concept. Alex was, therefore, able to follow inferential connections in both directions, 
meaning that he could follow the application of a higher-order concept to its lowerorder consequence and vice-versa. This provides strong evidence in favour of Alex meeting Brandom's two criteria for understanding a sufficient number of inferential connections for the possession of conceptual capabilities.

While Brandom could argue that Alex still has not demonstrated the ability to explicitly follow an argument to its consequence, it is worth noting the difficulties that humans often have with such a process (e.g. discriminating between valid and invalid arguments). Afterall, Brandom's project shows that the ability to make arguments explicit is dependent upon existing implicit inferential connections. While Alex's abilities to make it explicit would certainly have been limited, he was able to make enough explicit in order to show a grasp of the implicit structures necessary to use number concepts. He was able to appropriately apply number labels, use numbers as both concepts and objects, and understand at least some consequences of the application of those concepts. I do not mean for this conclusion to be a rejection of Brandom's inferentialism. Instead, it shows that there is room for a useful dialogue between Brandom's analysis of the necessary components of conceptual capabilities and Pepperberg's investigations into cognitive capacities of African greys. I think this dialogue deepens both approaches: showing the relevance of inferentialism for investigations into animal cognition and the relevance of empirical work for the claims of inferentialism.

\section{The Clever Hans Objection}

One way to resist this conclusion is to argue that Pepperberg's results show Alex performing a very clever trick to elicit a favourable response from his examiners. If Alex's squawks were prompted by unintentional cues, then Alex does not provide a counterexample to Brandom's declaration that parrots lack conceptual capabilities. A 
much discussed example is the horse Clever Hans, who at the beginning of the 20th Century became a celebrity for, not only his mathematical abilities, but his knowledge of musical theory and ability to read German. Hans' capabilities were so impressive that not only were his owner and the media convinced, but whole teams of scientists were as well (Trestman, 2015, p. 88). It was not until the biologist and psychologist Oskar Pfungst took over testing Hans that it became apparent that Hans' real competency was in reading body language. Hans was able to correctly answer the questions by tracking subconscious cues accidently provided by the researcher (p. 90).

Sensitive to these types of worries, Pepperberg experimented with using a box to hide the object from the examiner so that only the bird could see the object it was being asked to label. The problem with this approach was that it was hard to hold the bird's interest. Pepperberg (1999) writes "young birds do not necessarily sit quietly on perches during tests; they attempt to climb down, jump to the trainers for preening, and so forth. Trying to get these birds to attend to material in a box under such circumstances is next to impossible, but gaining their attention with a hand-held object works very well" (p. 33). Even still, Pepperberg (1999), like other animal behavior researchers, makes efforts to avoid cueing, such as randomizing the order of the questions, blinding the trials as much as possible (the listeners do not see the object the bird is trying to identify), and testing a variety of different types of questions (object, material, color, number, etc.) in a single test to avoid the animal leaning on contextual associations (pp. 29-31). While it is still possible to argue that these trials are not sufficiently blinded, it is worth noting that such doubts would also limit the ability of researchers who study the cognitive capabilities of human children. In tests involving human children, it is often the case that the researcher knows the child, the child sits in their parent's lap, and there are no physical barriers between the researcher and the child (Andrews, 2015, p. 11). 
It can still be asked, though, how well Alex fits the details of the Clever Hans case. Pfungst was able to figure out that Hans was not actually comprehending the questions and answers because when an examiner who did not know the answer asked a question, Hans could not provide the answer. But, since the labels that Alex used could be fairly idiosyncratic (e.g. banerry for apple), it was not always the case that Alex's examiner was aware of the correct answer (Pepperberg, 1999, p. 33). Hans' cues were primarily from the examiner posturally tensing up and then releasing tension. So, if Hans was tapping his hoof to indicate the answer to an addition problem, he would continue tapping until the examiner's "expectant tension" turned into "confirmatory relief" through minor involuntary movements in the head and neck (Trestman, 2015, 89-90). This type of cue was not available to Alex because Alex provided a word for how many objects were in a given set instead of counting them out. If Alex was simply providing the correct vocal articulation by reading inadvertent cues off his examiner, then, at the very least, they were much more sophisticated than the ones Hans picked up on. Furthermore, sometimes the examiner will make a mistake and scold a bird for a correct response but one of Pepperberg's birds will repeat the correct answer again even though the process encourages a "lose-shift strategy" (Pepperberg, 1999, p. 32). Worries that researchers are reading meaning into ambiguous squawks are mitigated by having researchers from other universities evaluate the recorded sounds from testing sessions, as well as sonographic analysis (Pepperberg, 2008).

Given these results, it seems highly unlikely that Alex was reading inadvertent cues off of his examiners in the way Hans was able to. But I suspect for some philosophers no possible evidence could provide reason to attribute conceptual capabilities to nonhuman animals. It is important to differentiate a healthy scientific skepticism from a humanistic solipsism, since the former is interested in evaluating 
actual claims, while the latter is merely an a priori bias. Assuming that parrots lack conceptual capabilities is not a neutral position. Boehrer (2011), in his book Animal Characters, shows how the current cultural status of parrots as mindless mimickers originates in sixteenth century satirical representations of Vatican decadence (pp. 74106). And as Andrews and Huss (2014) have argued, the denial of mental attributes to animals is an inappropriate null hypothesis since it makes stronger, less substantiated claims than are appropriate for one (pp. 721-724). So any claims that a denial of Alex's conceptual capabilities is the correct default attitude should be regarded with certain level of skepticism itself. While the Hans case provides reasons for being cautious when engaging in animal research that requires direct physical interaction with an animal, the care exercised in Pepperberg's research with Alex reflects those concerns.

\section{Conclusion}

Alex the parrot provides an interesting counterexample to the line of thinking, especially prevalent in Brandom's work, that all nonhuman animals are incapable of conceptual thought. Brandom has explicitly argued that the articulations that parrots make cannot be considered meaningful communication, since they lack the necessary inferential connections. I have appealed to Frege's analysis of number to argue that Alex's numerical capabilities necessarily come with inferential connections. Frege argued that number statements are statements about concepts, meaning that numerical capabilities come tied up with conceptual ones. While I hope to have provided a convincing argument that Frege's insight provides good reason to think that Alex had conceptual capabilities, this paper is also intended to highlight the relevance of Frege's insight for evaluating conceptual capabilities, even if one still doubts that Alex has them. 
The value that inferentialism can provide scientific investigations of animal cognition can come on both the training and the testing side. As I highlighted in my overview of the $\mathrm{M} / \mathrm{R}$ approach, Pepperberg and other researchers, in their emphasis on social and holistic learning, in contrast to previous more atomistic approaches, have discovered many of these possible lessons independently. Though Pepperberg states that numerical judgements require an extra cognitive step, Frege shows that numerical capacities are more significant than just being more cognitively complicated. While this paper has focused on Pepperberg's work with Alex and other grey parrots, similar numerical capabilities have been found in other species. While the most impressive results have been found in work with nonhuman primates, especially chimpanzees (see Beran, Perdue, \& Evans, 2014 for a useful overview), sophisticated abilities to make quantity discriminations have also been found in an incredibly diverse set of taxa (see Agrillo, 2014 for a useful overview). ${ }^{8}$ While these experimental results certainly hint that chimpanzees and other nonhuman species might meet Brandom's criteria for conceptual capacities, fully evaluating these empirical results is beyond the scope of this paper.

I also think these lessons cut the other way as well. Inferentialism and other approaches born out of the latter half of 20th Century analytic philosophy that make universal claims about what animals cannot do without citing any empirical research should proceed with more caution. While there still might be good reasons to be skeptical of some of the claims that scientists make, there are also good reasons to be skeptical of completely a priori investigations into the cognitive capacities of animals. So while, I expect inferentialists will still be resistant to the conclusions I have presented here, at the very least, any attempt to dismiss them will require an interaction between theoretical and empirical work. 
Acknowledgements: I would like to deeply thank Andrew Fenton, Letitia Meynell, Michael

Hymers, Gregory Lavers, Andrew Lopez, Ebony Demers, and everyone who gave me

incredibly useful feedback on an earlier version that I presented for a Dalhousie Philosophy

Colloquium. The extended debate I had with Darren Abramson over these issues also played an invaluable role in the development of this paper, and I hope I've met some of his many strong objections.

${ }^{1}$ The diversity of approaches and disciplines that make up the field of animal cognition means that it can be easier to find disagreement than consensus. Despite disagreements among cognitive scientists and a growing group of philosophers who are willing to take the attribution of cognitive categories to nonhuman animals seriously, it is still possible to make some general divisions. Andrews and Huss (2014) argue that skeptics within the field are "selective" meaning that they skeptical about whether it is appropriate to apply this or that category to the mental life of animals (pp. 712-713). Whereas there is still a significant number of philosophers who are "categorical" skeptics who "pre-empirically" dismiss the possibility of studying animal cognition (p. 712). But even keeping this division clear can be a little fuzzy since categorical skeptics are often motivated by a selective approach. So some theoretical approaches are categorically skeptical because they see animals as failing to possess one crucial capability upon which the existence of all the cognitive capabilities depend (e.g. language, concepts, metacognition). So while these divisions are certainly messy, it can still truthfully be said that there is a significant lineage of philosophers who are categorically skeptical while the majority of scientists who study animal cognition are more selective in their skepticism.

${ }^{2}$ It is important to note that while Brandom's understanding of concepts and conceptual capabilities may be influential, it is also controversial. The enormity of the philosophical, psychological, and biological literature on concepts means, unfortunately, I can only acknowledge the existence of this fascinating debate here.

${ }^{3}$ There have been several recent attempts to broaden the scope of Brandom's inferentialism (e.g. Griffin, 2017) and more broadly, neopragmatism (e.g. Danón, 2018), to make room for nonlinguistic animals. While I am sympathetic with the aims of these projects, this paper does not attempt to modify Brandom's framework, instead it shows that there are nonhuman animals who already fit within it.

${ }^{4}$ In a typical passage, Kant (1785/1996) writes "the human being and in general every rational being exists as an end in itself..." (p. 79). The move here is to bind human beings to a greater category so the attribution of specialness to human beings comes from their belonging to a category like rationality that can be philosophically justified instead of a baldly asserted speciesism. In order to avoid the question-begging consequences of such a move, Brandom sets up his project as "a story about practices that are sufficient to confer propositionally contentful intentional states on those who engage in them, without presupposing such states on the part of practitioners" (1994, p. 7)

${ }^{5}$ I have used Dummett's version since the conclusion he reaches only functions as a premise in the passage from Frege $(1884 / 1950, \S 31)$.

${ }^{6}$ An open and interesting question is whether or not Alex's conceptual capabilities played a functional role outside of the tasks Pepperberg gave him.

${ }^{7}$ Brandom (1994) approvingly cites this passage, summarizing the insight as: "counting is intelligible only with respect to a sortal concept" (p. 438).

${ }^{8}$ I would like to thank an anonymous reviewer for insisting on the importance of this work. 


\section{References:}

Agrillo, C. (2015). Numerical and arithmetic abilities in non-primate species. In R. C. Kadosh \& A. Dowker (Eds.), The Oxford Handbook of Numerical Cognition (pp. 214-236). Oxford, UK: Oxford University Press.

Allen, C. \& Hauser, M. (1991). Concept attribution in nonhuman animals: Theoretical and methodological problems in ascribing complex mental processes. Philosophy of Science, 58(2), 221-240.

Andrews, K (2015). A role for folk psychology in animal cognition research. Animal Studies Repository, 66. Retrieved from http://animalstudiesrepository.org/acwp_arte/66

Andrews, K. (2016). Animal cognition. In E. N. Zalta (Ed.), Stanford Encyclopedia of Philosophy, (pp. 1-116). Retrieved from https://plato.stanford.edu/archives/sum2016/entries/cognition-animal/

Andrews, K. \& Huss, B. (2014). Anthropomorphism, anthropectomy, and the null hypothesis. Biology \& Philosophy, 29(5), 711-729.

Beran, M. J., Perdue, B. M., \& Evans, T. A. (2015). Monkey mathematical abilities. In R. C. Kadosh \& A. Dowker (Eds.), The Oxford Handbook of Numerical Cognition (pp. 237-257). Oxford, UK: Oxford University Press.

Bermúdez, J. L. (2003). Thinking without words. New York, NY: Oxford University Press.

Boehrer, B. T. (2011). Animal characters: Nonhuman beings in early modern literature. Philadelphia, PA: University of Pennsylvania Press.

Brandom, R. (1994). Making it explicit: Reasoning, representing, and discursive commitment. Cambridge, MA: Harvard University Press. 
Brandom, R. (2000). Articulating reasons: An introduction to inferentialism.

Cambridge, MA: Harvard University Press.

Danón, L. (2018). Neo-pragmatism, primitive intentionality and animal minds. Philosophia, 1-20.

Davidson, D. (1982). Rational animals. Dialectica, 36, 317-328.

Dummett, M. (2010). The nature and future of philosophy. New York, NY: Columbia University Press.

Frege, G. (1950). The foundations of arithmetic. J. L. Austin, Trans. Oxford, UK:

Blackwell. Original work published in 1884.

Frege, G. (1997). On concept and object. In M. Beany (Ed.), The Frege Reader (pp.181193). Oxford, UK: Blackwell. Original work published in 1892.

Griffin, N. (2017). Brandom and the brutes. Synthese, 1-27.

Herrnstein, R. J., Loveland, D. H., \& Cable, C. (1976). "Natural concepts in pigeons.” Journal of Experimental Psychology: Animal Behavior Processes, 2(4), 285302.

Kant, I. (1996). The groundwork of the metaphysics of morals. In M. J. Gregor, Trans. (Ed.), Practical Philosophy (pp. 37-108). Cambridge, UK: Cambridge University Press. Original work published in 1785.

Klement, K. C. (2012). Frege's changing conception of number. Theoria , 78(2), 146167.

Pepperberg, I. M. (1999). The Alex studies: Cognitive and communicative abilities of grey parrots. Cambridge, MA: Harvard University Press.

Pepperberg, I. M. (2006a). Grey parrot numerical competence: A review. Animal Cognition, 9(4), 377-391.

Pepperberg, I. M. (2006b). Intelligence and rationality in parrots. In S. Hurley \& M. 
Nudds (Eds.), Rational Animals? (pp. 469-488). Oxford, UK: Oxford University Press.

Pepperberg, I. M. (2008). Peer-reviewed parrot studies speak for themselves, as he did. Nature, 456(166), 166.

Pepperberg, I. M. (2012). Further evidence for addition and numerical competence by a grey parrot (psittacus erithacus). Animal Cognition, 15(4), 711-717.

Stich, S. P. (1978). "Do animals have beliefs?” Australasian Journal of Philosophy, 57(1), 15-28.

Trestman, M. (2015). Clever Hans, Alex the parrot, and Kanzi: What can exceptional animal learning teach us about human cognitive evolution? Biological Theory, 10(1), 86-99.

Wynn, K. (1990). Children's understanding of counting. Cognition, 36(2), 155-193.

Zalta, E. N. (2016). Gottlob Frege. In E. N. Zalta (Ed.), The Stanford Encyclopedia of Philosophy, (pp. 1-77). Retrieved from https://plato.stanford.edu/entries/frege/ 